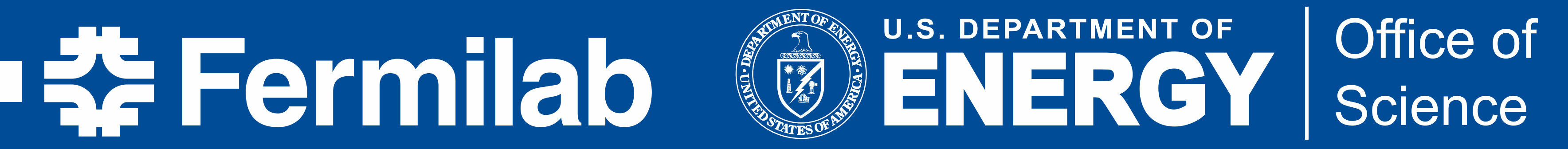

\section{A Concept for Ultra-High Energy Electron and Positron Test Beams at Fermilab}

Jamal Johnson

National Conference on Undergraduate Research 2019

Kennesaw State University, Kennesaw, Georgia, April 10-13, 2019

This manuscript has been authored by Fermi Research Alliance, LLC under Contract No. DE-AC02-07CH11359 with the U.S. Department of Energy, Office of Science, Office of High Energy Physics. 


\section{CERN $\mathrm{e}^{ \pm}$Test Beams and 2 Year Shutdown Impact}

Experimenters looking for energies higher than $30 \mathrm{GeV}$ will have no current comparable alternatives when CERN test beams are shutdown for 2 years at the end of 2018 [10].

- Alternate Lab Electron and Positron Test Beam Limits

- DESY

- Under $10 \mathrm{GeV} / \mathrm{c}$

- SLAC

- Limited to $25 \mathrm{GeV} / \mathrm{c}$

- Fermilab

- Ranged from 1 - $32 \mathrm{GeV}$ (highest momenta of $\sim 31.9986 \mathrm{GeV} / \mathrm{c}$ )

- Mixed Species

- A unique opportunity to attract a new group of users has presented itself. As CERN $\mathrm{e}^{ \pm}$test beams are mixed species, providing higher purity, ultra high energy beams has been requested [1][2][3]. 


\section{Assumed Primary Mechanism for Obtaining Ultra High Energy $\mathrm{e}^{ \pm}$}

A rare decay mode for charged pions is believed to be the most effective mechanism [4].

- Branch ratio : 0.000123

- Charged pions are to be produced as secondaries from $120 \mathrm{GeV} / \mathrm{c}$ proton beam on target.

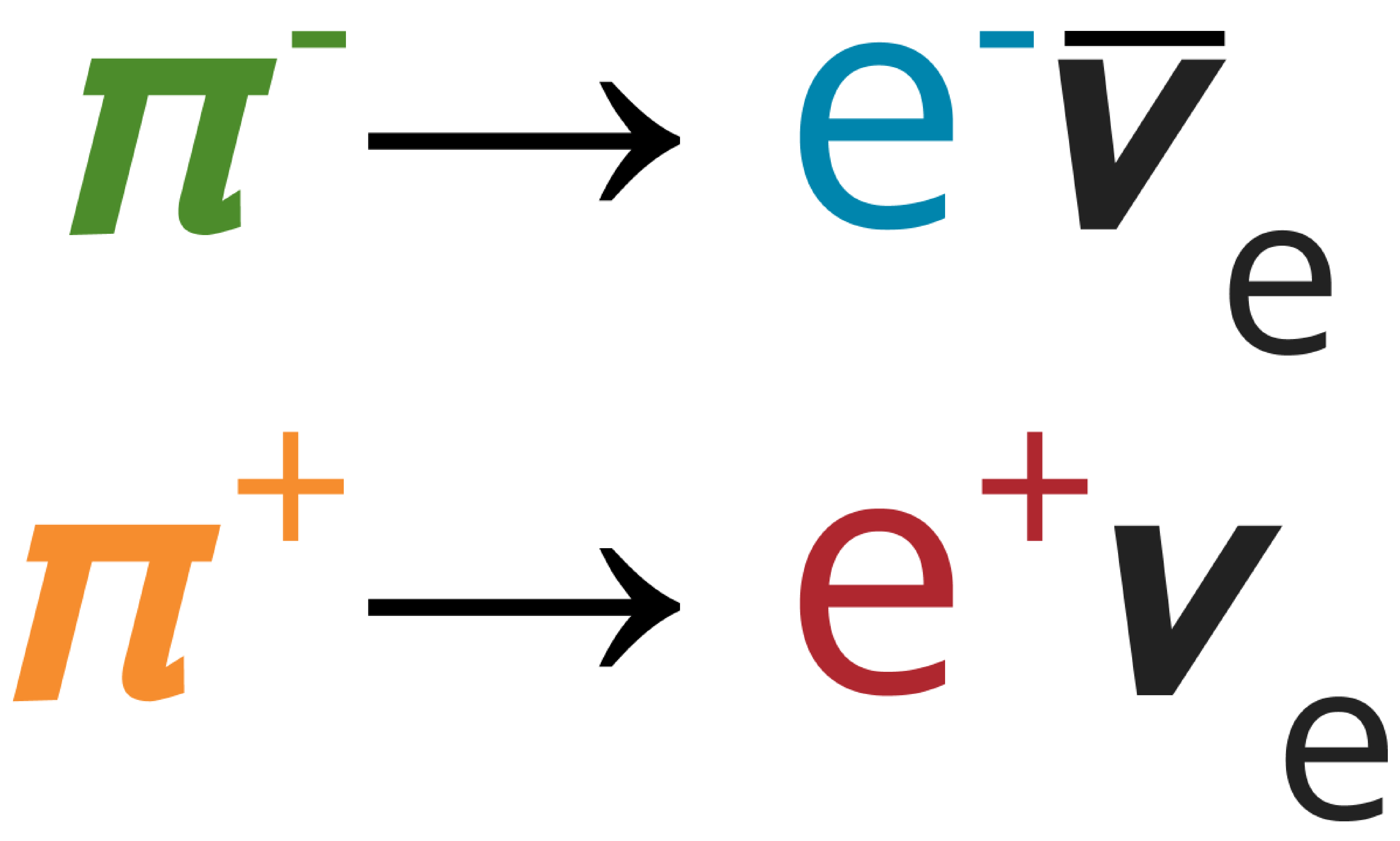




\section{Fractional Yield from Charged Pion Decay and $\mathrm{e}^{ \pm}$at Test Site}

MTest distance from M01 Target Station: $460 \mathrm{~m}$. $500 \mathrm{~m}$ used for calculation to account for additional path length from separation optics.
- Average of $50 \mathrm{GeV} / \mathrm{c}$ momentum bite, mean lifetime, and mass for $\pi^{ \pm}$used
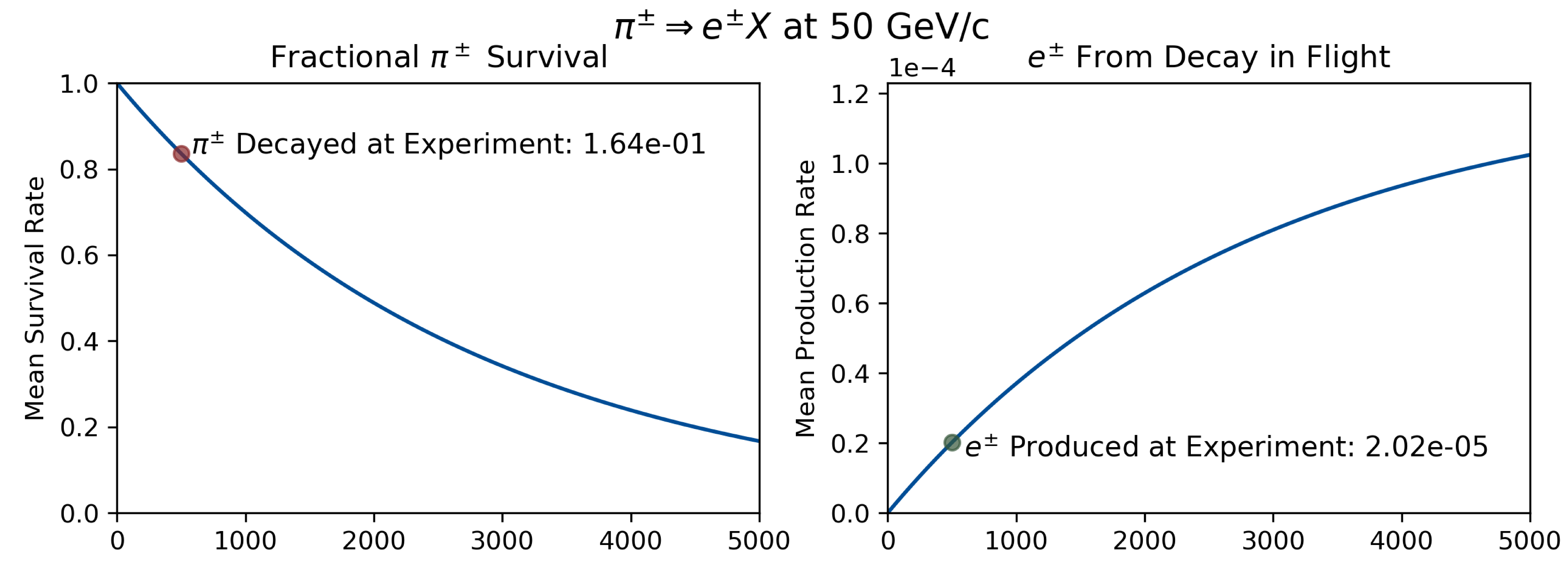

Distance from Center of Target $(\mathrm{m})$ 


\section{Minimum Production Needed for Requested Spill}

\section{M01 target station is referenced which receives 2 e11 proton beam}

\section{- Requested minimum spill of $5 \mathrm{e} 3 \mathrm{e}^{ \pm}$at experiment}

\begin{tabular}{|c|c|c|c|c|c|}
\hline \multicolumn{7}{|c|}{ Mrompt $\pi^{ \pm}:$} \\
\hline $\begin{array}{c}\text { Momentum } \\
(\mathrm{GeV} / \mathrm{c})\end{array}$ & $\begin{array}{c}\text { Relativistic Factor } \\
\gamma\end{array}$ & $\begin{array}{c}\text { Velocity } \\
\text { (fraction of } \mathrm{c})\end{array}$ & $\begin{array}{c}\text { Flight Time to } 500 \mathrm{~m} \\
(\mathrm{~s})\end{array}$ & $\begin{array}{c}\text { Pion Decay } \\
(\text { fraction of } 1)\end{array}$ & $\begin{array}{c}\text { Minimum Production Needed with 2e11 POT } \\
\left(\pi^{ \pm} / \mathrm{proton}\right)\end{array}$ \\
\hline 47.5 & 340.3320469 & 0.999995683 & $1.667827676 \mathrm{E}-06$ & 0.171588516 & $1.1845 \mathrm{E}-02$ \\
\hline 50 & 358.2441091 & 0.999996104 & $1.667826974 \mathrm{E}-06$ & 0.163754478 & $1.2412 \mathrm{E}-02$ \\
\hline 52.5 & 376.1561784 & 0.999996466 & $1.667826370 \mathrm{E}-06$ & 0.156602722 & \\
\hline
\end{tabular}

\begin{tabular}{|c|c|c|c|c|c|}
\hline \multicolumn{7}{|c|}{$\begin{array}{c}\text { Prompt } \pi^{ \pm}: \\
\text {Minimum Production For 5E04 } \mathrm{e}^{ \pm} \text {at Experiment for 40, 50, 60, 70, and 80 GeV/c }\end{array}$} \\
\hline $\begin{array}{c}\text { Momentum } \\
(\mathrm{GeV} / \mathrm{c})\end{array}$ & $\begin{array}{c}\text { Relativistic Factor } \\
\gamma\end{array}$ & $\begin{array}{c}\text { Velocity } \\
(\text { fraction of c) }\end{array}$ & $\begin{array}{c}\text { Flight Time to 500 m } \\
(\mathrm{s})\end{array}$ & $\begin{array}{c}\text { Pion Decay } \\
\text { (fraction of } 1)\end{array}$ & $\begin{array}{c}\text { Minimum Production Needed with 2e11 POT } \\
\left(\pi^{ \pm} / \mathrm{proton}\right)\end{array}$ \\
\hline 40 & 286.5959154 & 0.999993913 & $1.667830629 \mathrm{E}-06$ & 0.200318118 & $1.0146 \mathrm{E}-02$ \\
\hline 50 & 358.2441091 & 0.999996104 & $1.667826974 \mathrm{E}-06$ & 0.163754478 & $1.2412 \mathrm{E}-02$ \\
\hline 60 & 429.8924192 & 0.999997294 & $1.667824988 \mathrm{E}-06$ & 0.138454594 & $1.4680 \mathrm{E}-02$ \\
\hline 70 & 501.5407958 & 0.999998012 & $1.667823791 \mathrm{E}-06$ & 0.119915958 & $1.6950 \mathrm{E}-02$ \\
\hline
\end{tabular}




\section{Target Material Selection Parameters}

- Minimizing Nuclear Interaction Length $\left(\lambda_{n}\right)$

- Describes Interaction of heavy particles with nuclei

- Charged pions are produced from nuclear interactions.

- Maximizing Pion Interaction Length $\left(\lambda_{\pi}\right)$

- Describes Interaction of Pions within a material

- Longer length should allow for more to escape.
- Maximizing Radiation Length $(\chi)$

- Describes the effect of multiple small angle deflections from Coulomb interaction

- Longer lengths result in less scattering [5]. 


\section{Material Optimization}

Production potential for charged pions and minimal emittance are what is essentially compared.

Beryllium was selected as it is very low on both scales and there is currently a sample inhouse.

Target Material Evaluation

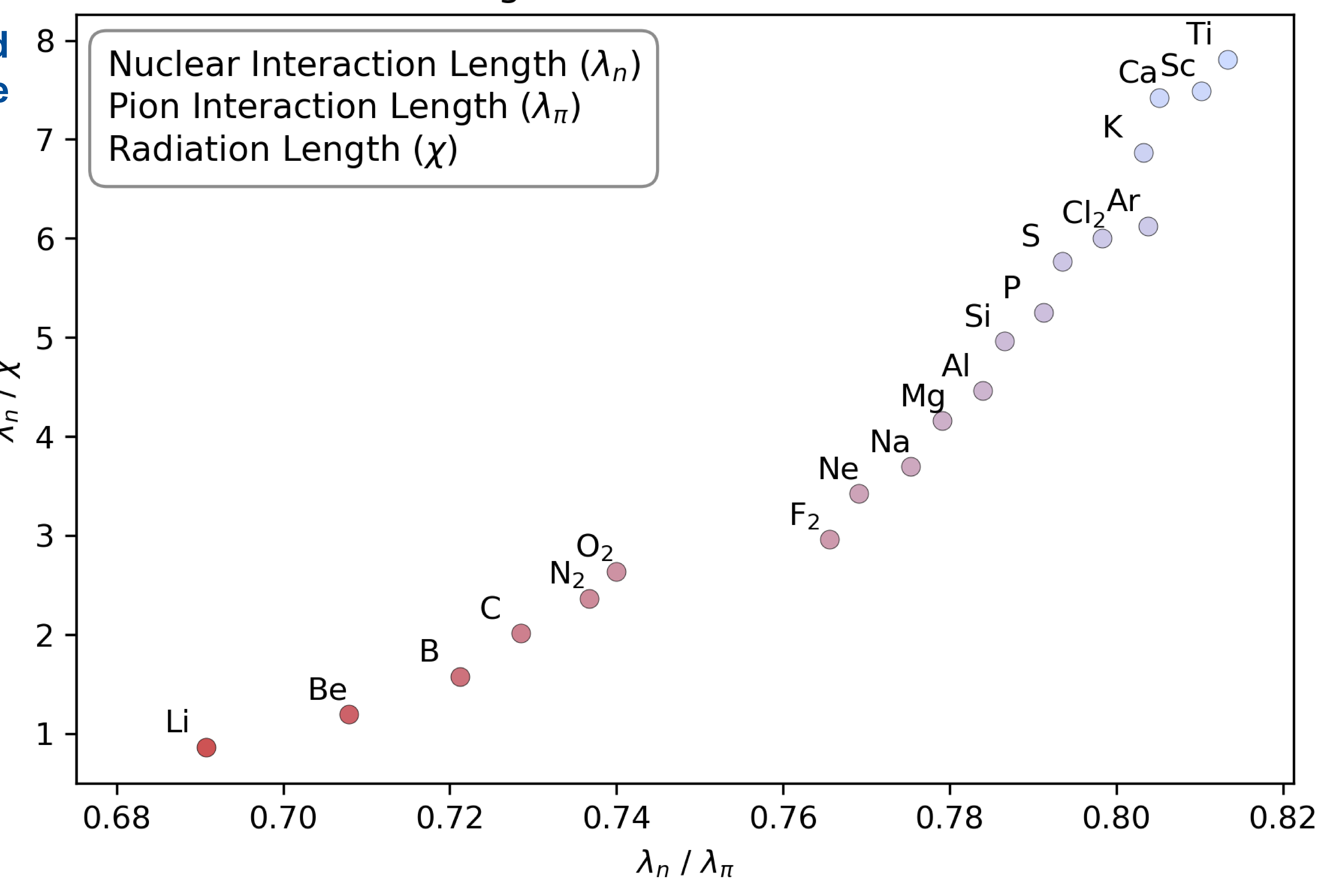

Nuclear Interaction Length $\left(\lambda_{n}\right)$

Pion Interaction Length $\left(\lambda_{\pi}\right)$

$\succsim$




\section{Primary Tools of Investigation}

- G4Beamline 3.04

- Simulates the passage and interactions of particles with matter

- Based on GEANT4, it is optimized for beamline design [7]

- Output of GEANT4 is a Monte Carlo text file containing kinematical variables for each particle received at a user defined virtual detector

- Processes come from comprehensive GEANT4 physics lists [8]

- Monte Carlo Method

- A statistical method that governs probabilities for secondary particle production

- Uses randomly generated inputs for physics processes to cover the spectrum of outcomes [9]

- Results produced are expressed as the mean of the normal (Gaussian) distribution

- 1 unit of standard deviation $(\sigma)$ for the distribution of the returned value $N$ may be obtained by taking the root of $N$

- Python 3.6.4

- Numpy, SciPy, and Matplotlib libraries used for analysis after parsing Monte Carlo 


\section{Secondary Particle Production and Preliminary Design}
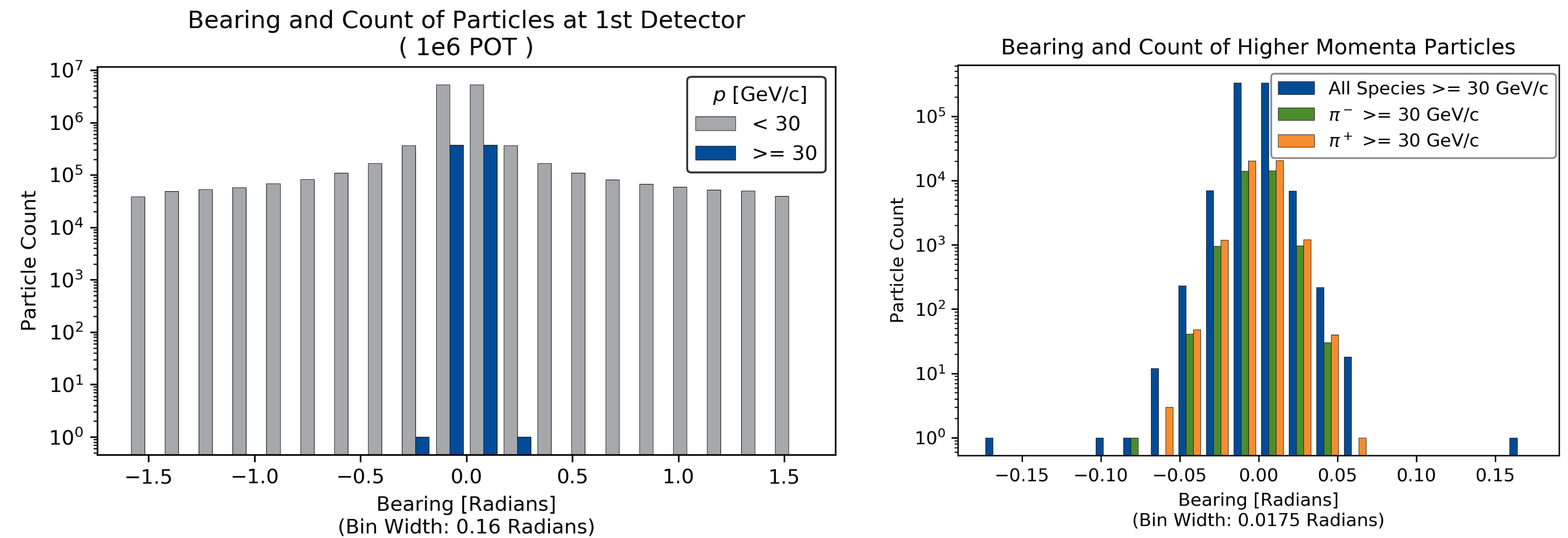

Initial simulations to understand the angular and energy spread of secondaries was done using $120 \mathrm{GeV} / \mathrm{c}$ proton beam at 1e4 events and a Be target. Results shown are from higher statistics obtained from $1 \mathrm{e} 6$ protons on target (POT). 


\section{Preparing for Optics}

- As large solid angles cannot be transported, collimation would be needed.

- 2 inch vertical aperture $1 \mathrm{~m}$ from the center of target planned

- Virtual detector was modified to perform this pitch cut.

- Initially a large disk immediately in front of target, detector redesigned as a cylinder $1 \mathrm{~m}$ in radius and 2 inches long. 


\section{G4Beamline Visualization Mode}

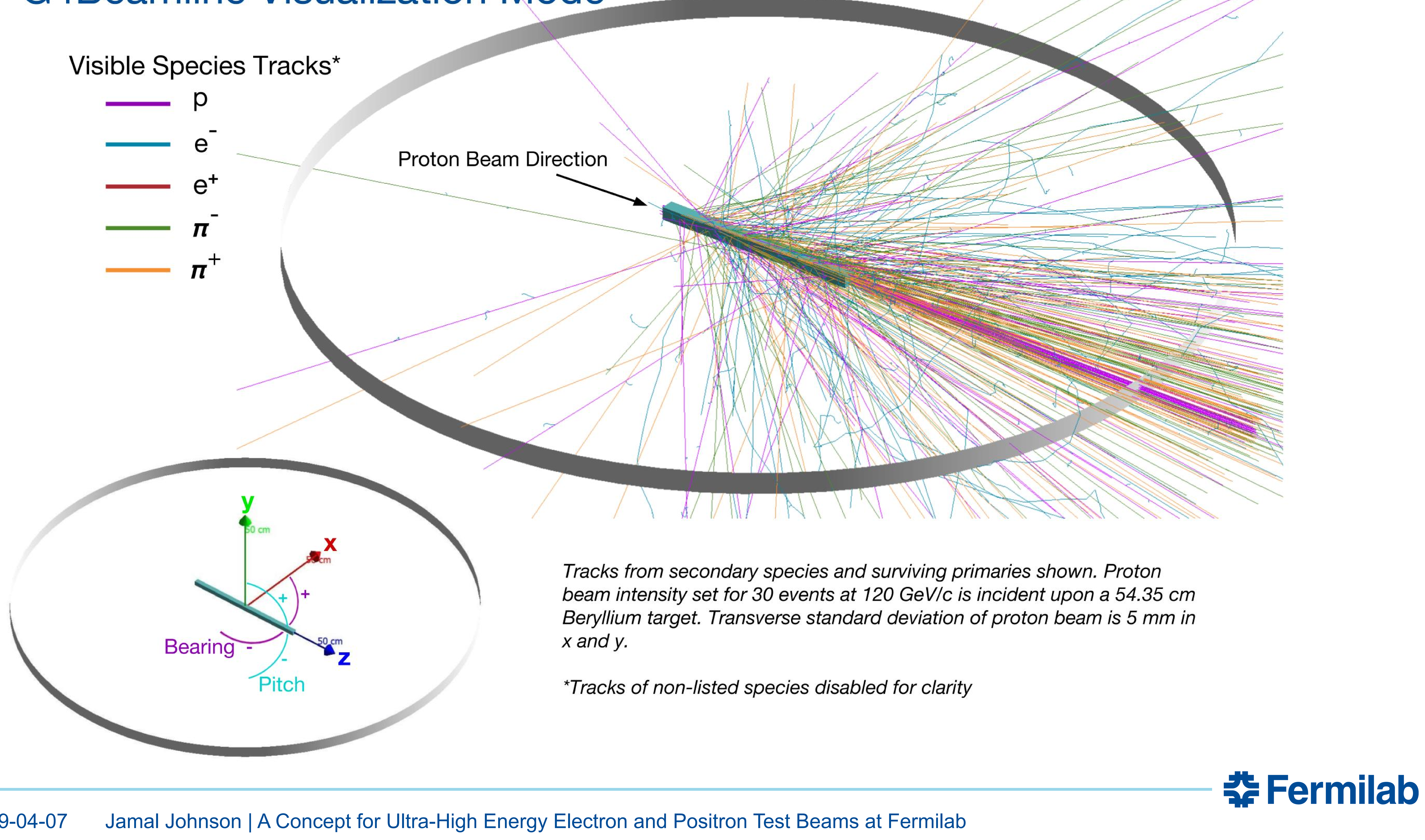




\section{Dimensional Optimization for Charged Pion Production}

$\pi^{-}$Production Per Proton vs Be Target Length (1e04 POT)
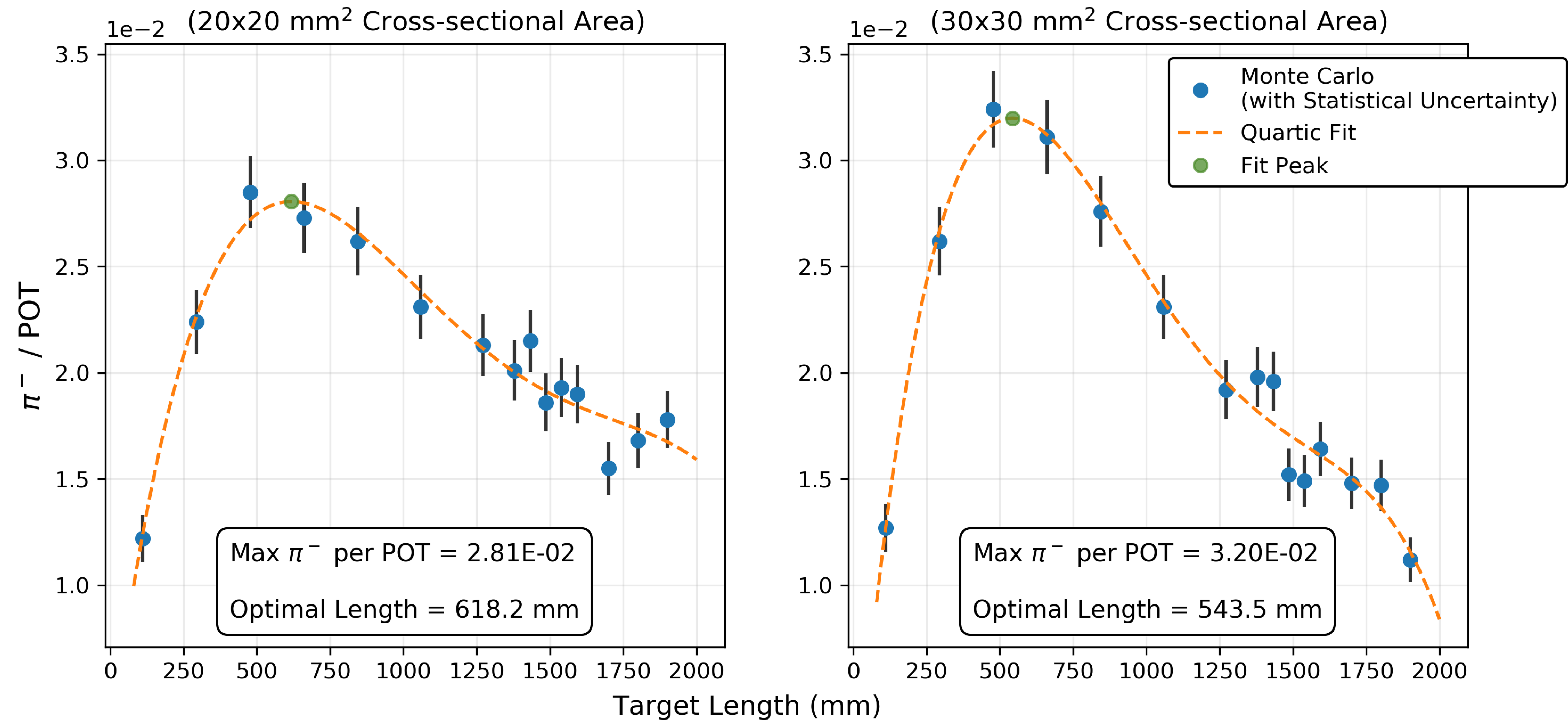

Target Length $(\mathrm{mm})$ 


\section{(continued for $\pi^{+}$)}

$\pi^{+}$Production Per Proton vs Be Target Length

\section{(1e04 POT)}
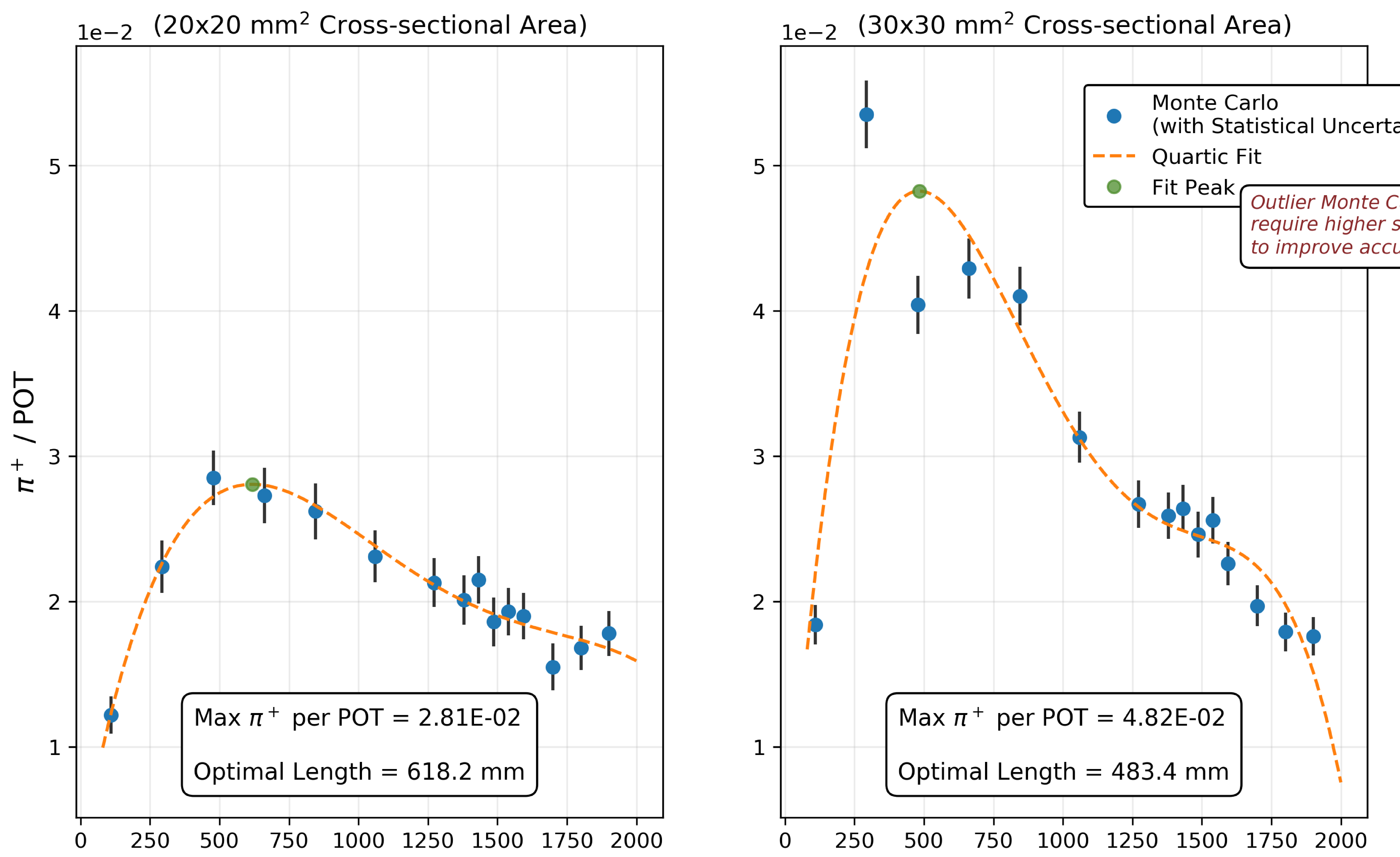

Target Length $(\mathrm{mm})$

Cross-sectional area of $30 \times 30 \mathrm{~mm}^{2}$ gave significantly greater production per proton on target. 


\section{Unexpected High Energy Prompt Electrons and Positrons}

Momenta and Count of $e^{ \pm}$at 1st Detector $\left(\pi^{-}\right.$Optimized $)$

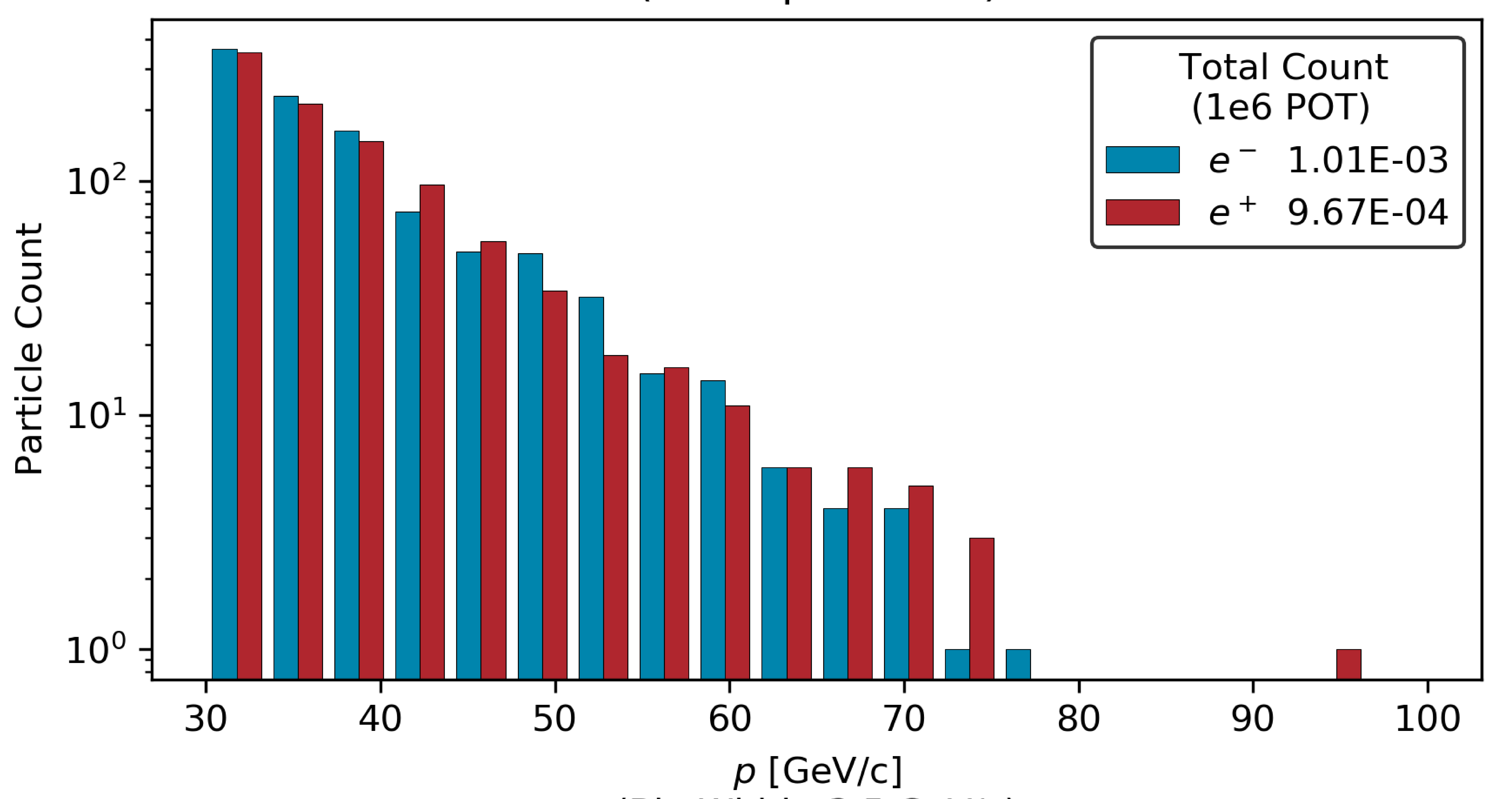

(Bin Width: $3.5 \mathrm{GeV} / \mathrm{c}$ )
- Detector inspection after running $1 \mathrm{e} 6$ protons on $\pi^{-}$ optimized target revealed significant prompt $\mathrm{e}^{ \pm}$ production.

- Of the 63 processes running under the FTFP_BERT physics list, only those capable of yielding $\mathrm{e}^{ \pm}$were targeted during the investigation of the physics responsible. 


\section{Investigation of Physics Responsible for Prompt $\mathrm{e}^{ \pm}$}

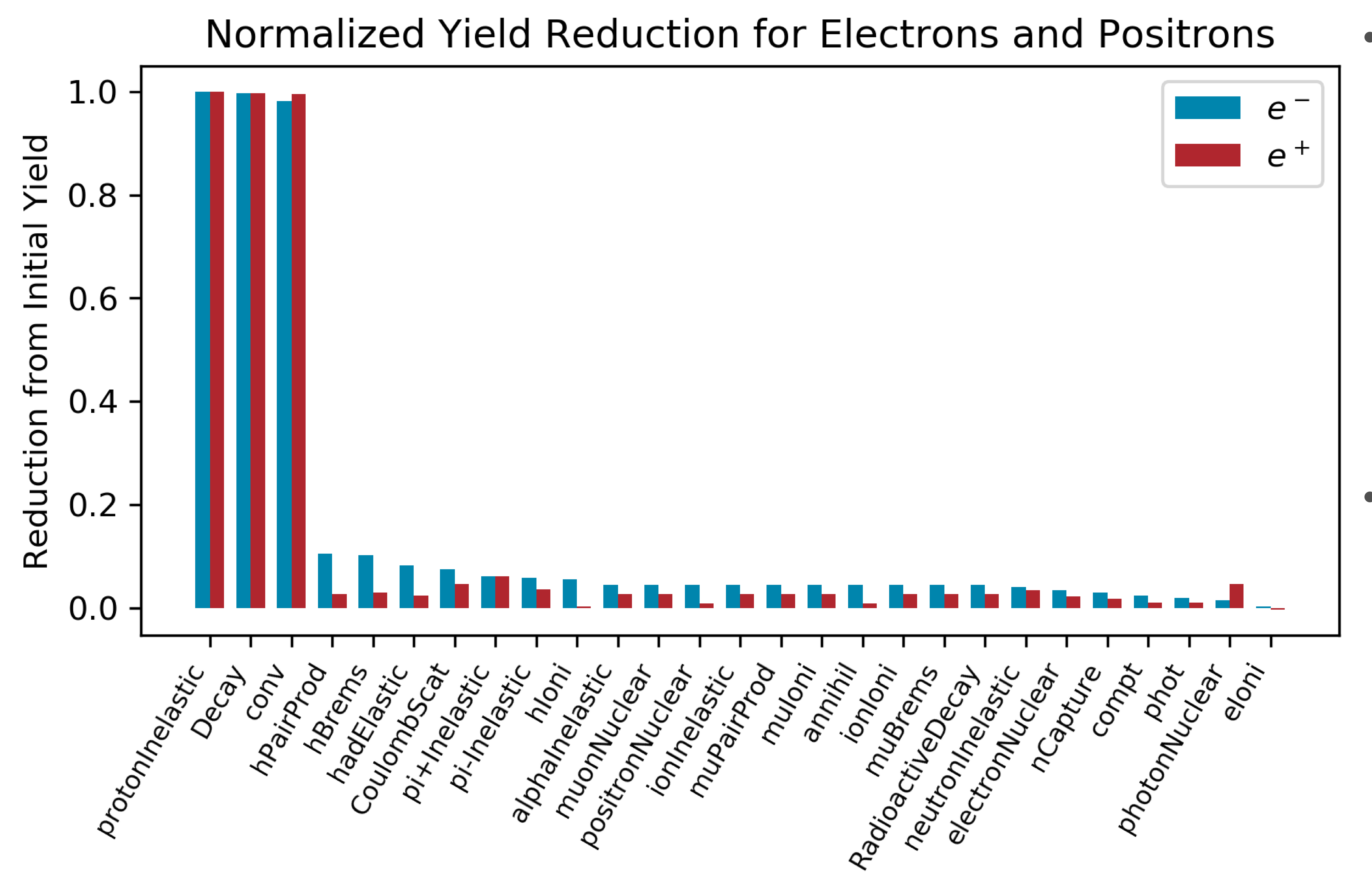

- Individual processes were disabled before running 1 e6 events and recording the normed $\mathrm{e}^{ \pm}$yield. The process was then enabled before disabling the next process and repeating the procedure.

- Disabling the proton inelastic, particle decay, or gamma conversion to $\mathrm{e}^{+} \mathrm{e}^{-}$ processes severed the reaction chain responsible for nearly all prompt high energy $e^{ \pm}$. 


\section{Prompt Electron and Positron Analysis}

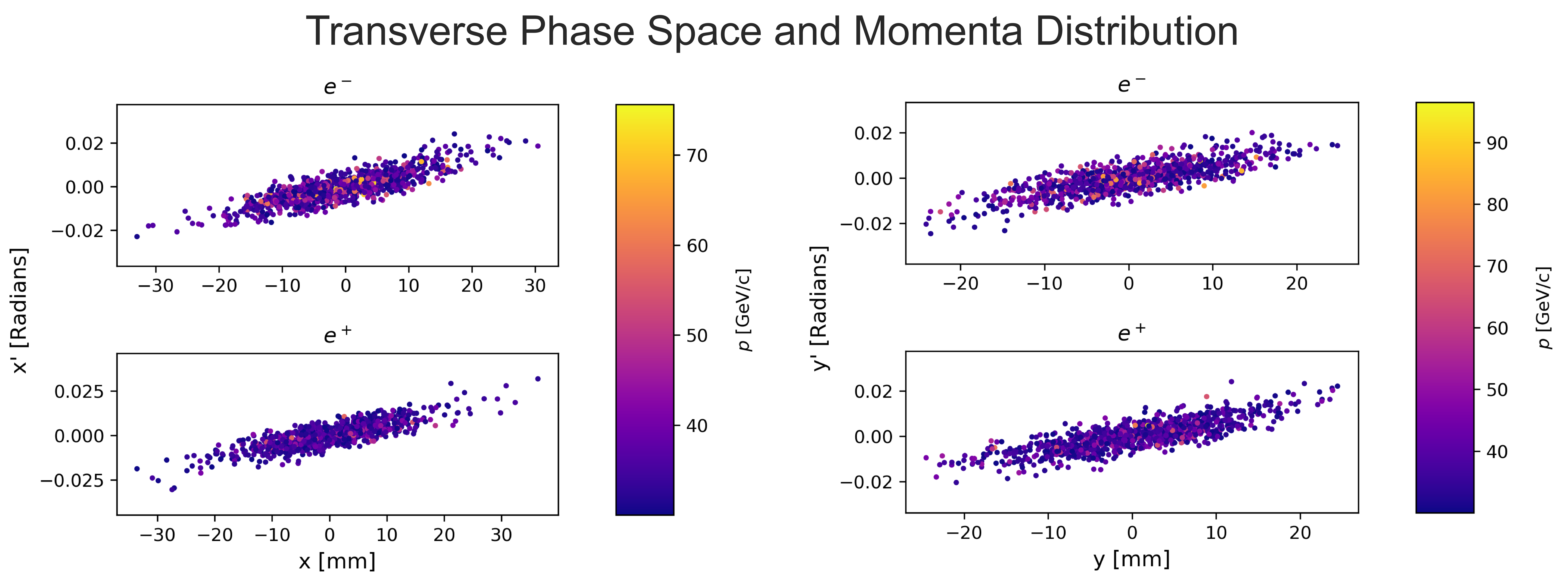

Phase Space is a conceptual method of seeing how the system changes by plotting the amplitude of particle oscillations against their derivatives (or positions as defined earlier). This is essential in characterizing the periodic motion of the beam. 


\section{Dimensional Optimization for Prompt e ${ }^{\ddagger}$ Production}

$e^{-}$Production Per Proton vs Be Target Length

(1e04 POT)
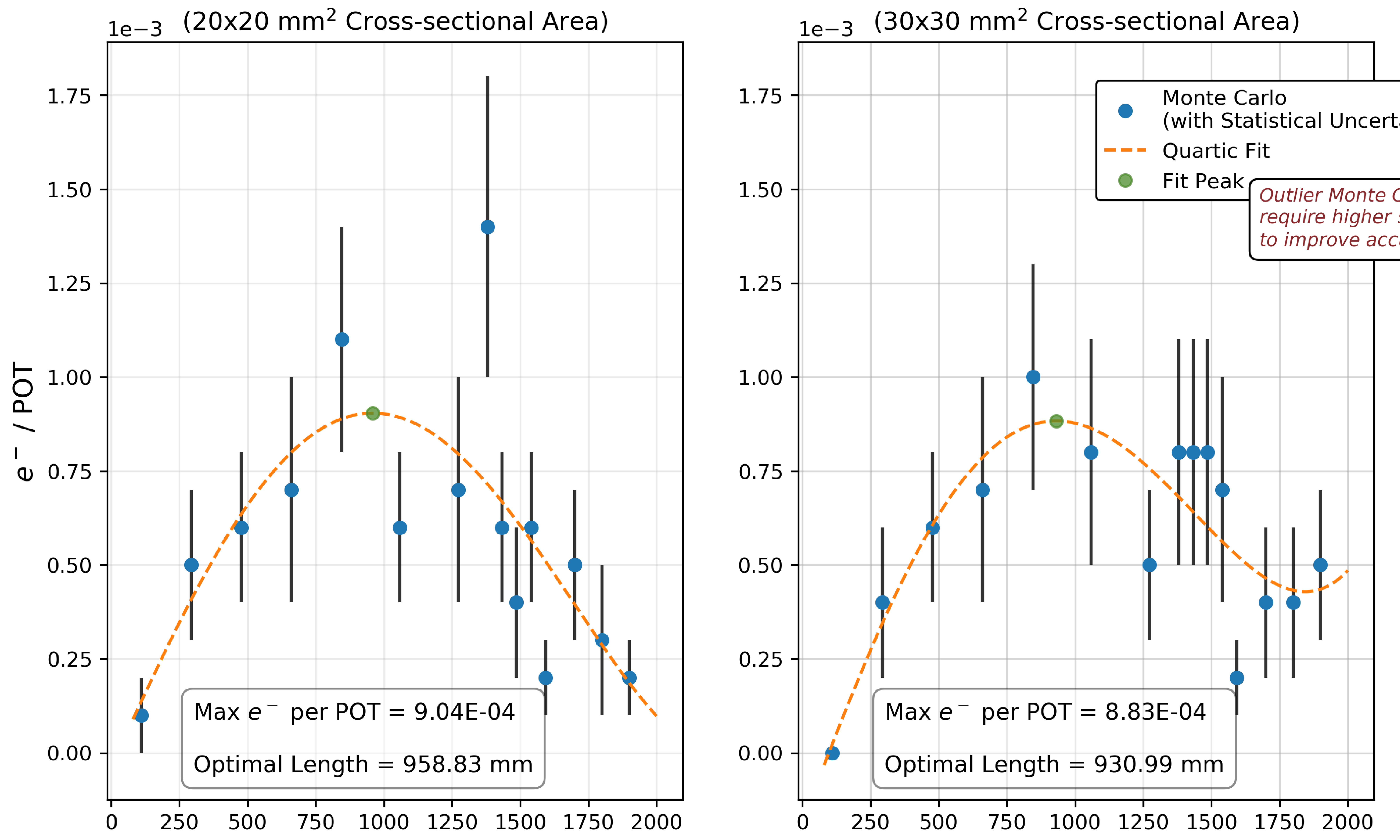

Target Length $(\mathrm{mm})$

Statistics from $1 \mathrm{e} 4$ protons on target revealed better e- production with $20 \times 20 \mathrm{~mm}^{2}$ cross-sectional area. 


\section{(continued for $\mathrm{e}^{+}$)}

\section{$e^{+}$Production Per Proton vs Be Target Length}

(1e04 POT)
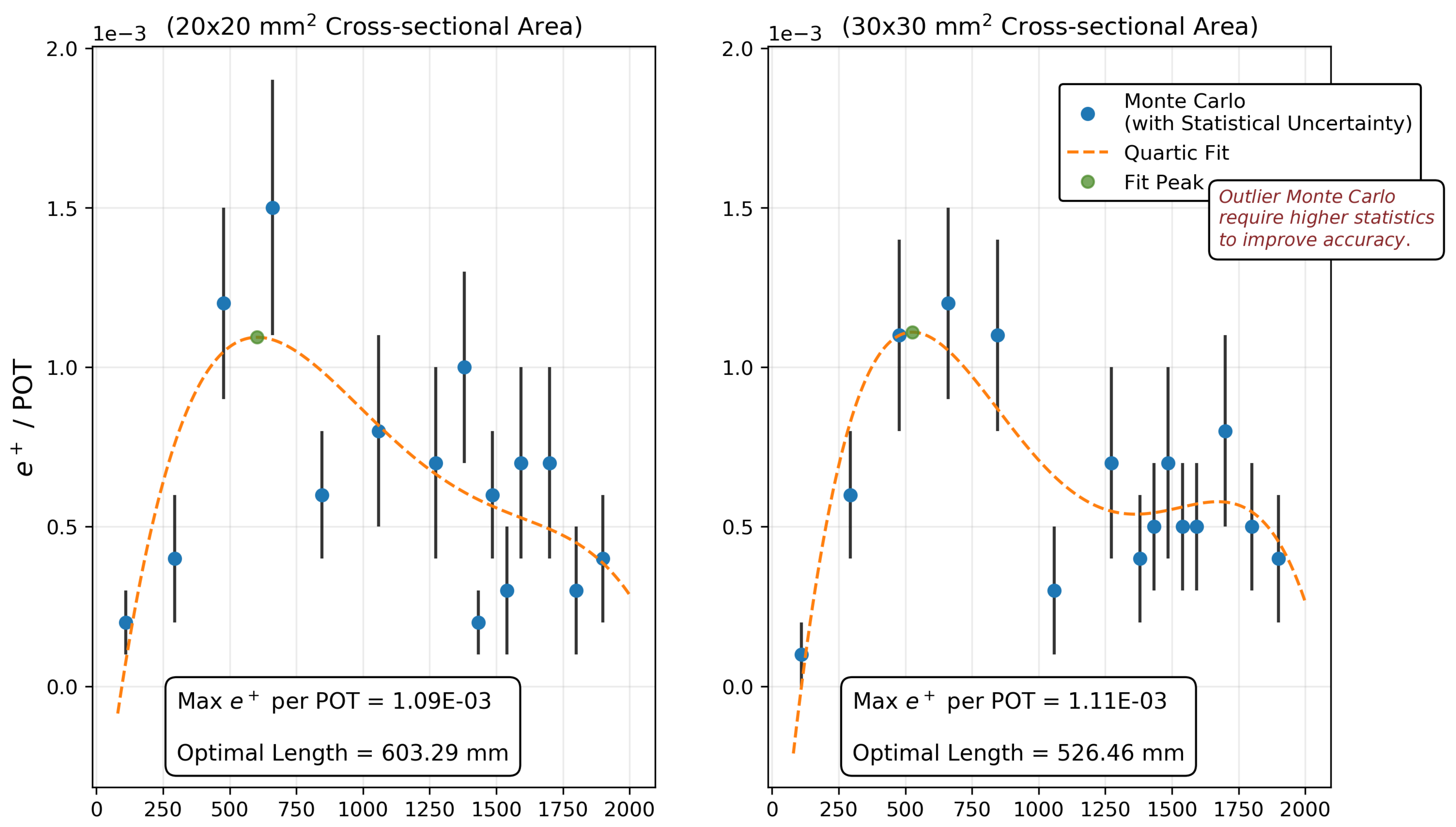

Target Length $(\mathrm{mm})$ 


\section{Strong Focusing Basics - Part 1 : Quadrupole Field Strength}
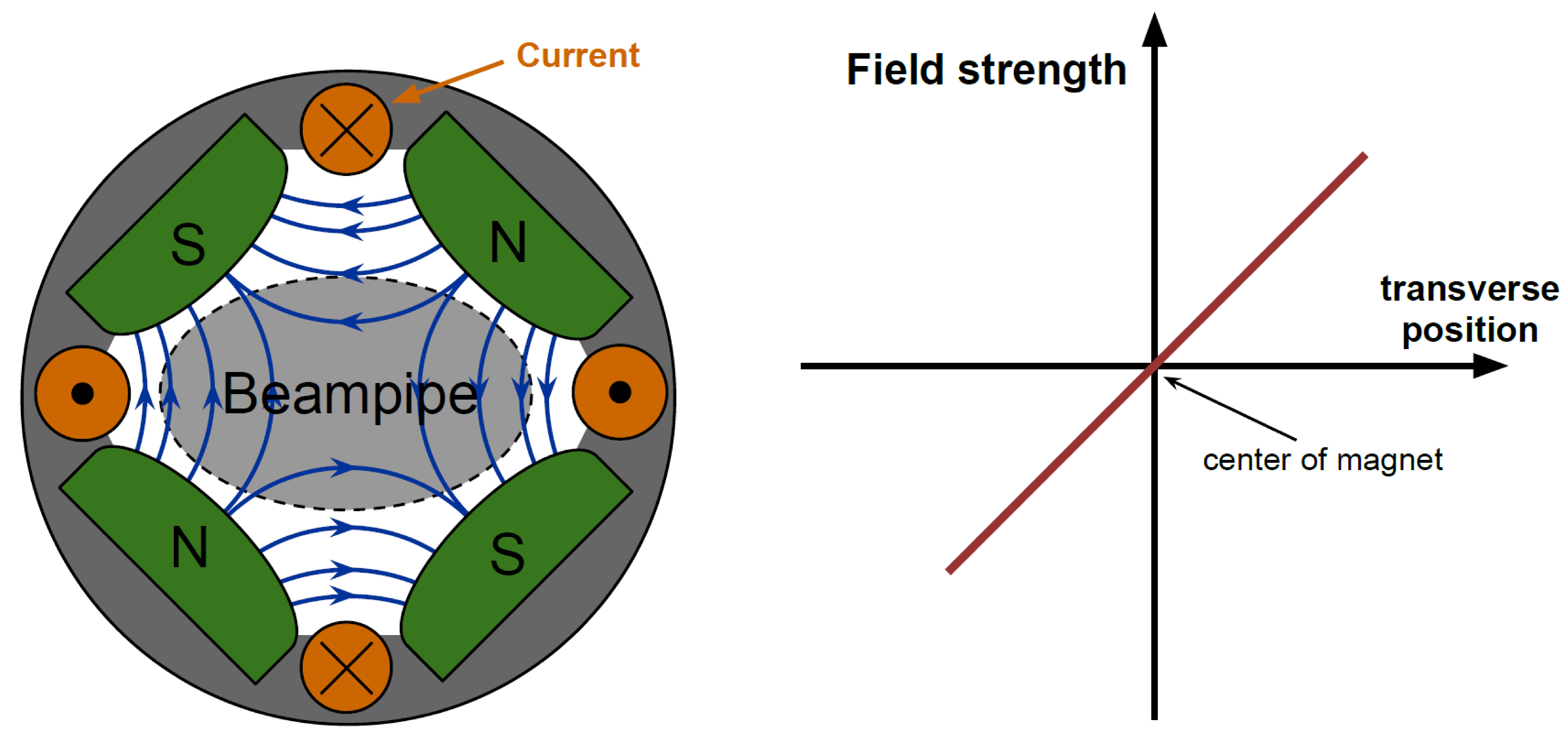

Charged particles displaced transversely from the center of the magnet interact with the magnet's field. Field strength increases linearly so the further off the desired path the more the particle is focused in one plane and defocused in the other [6]. 


\section{Strong Focusing Basics - Part 2 : The Alternating Gradient}

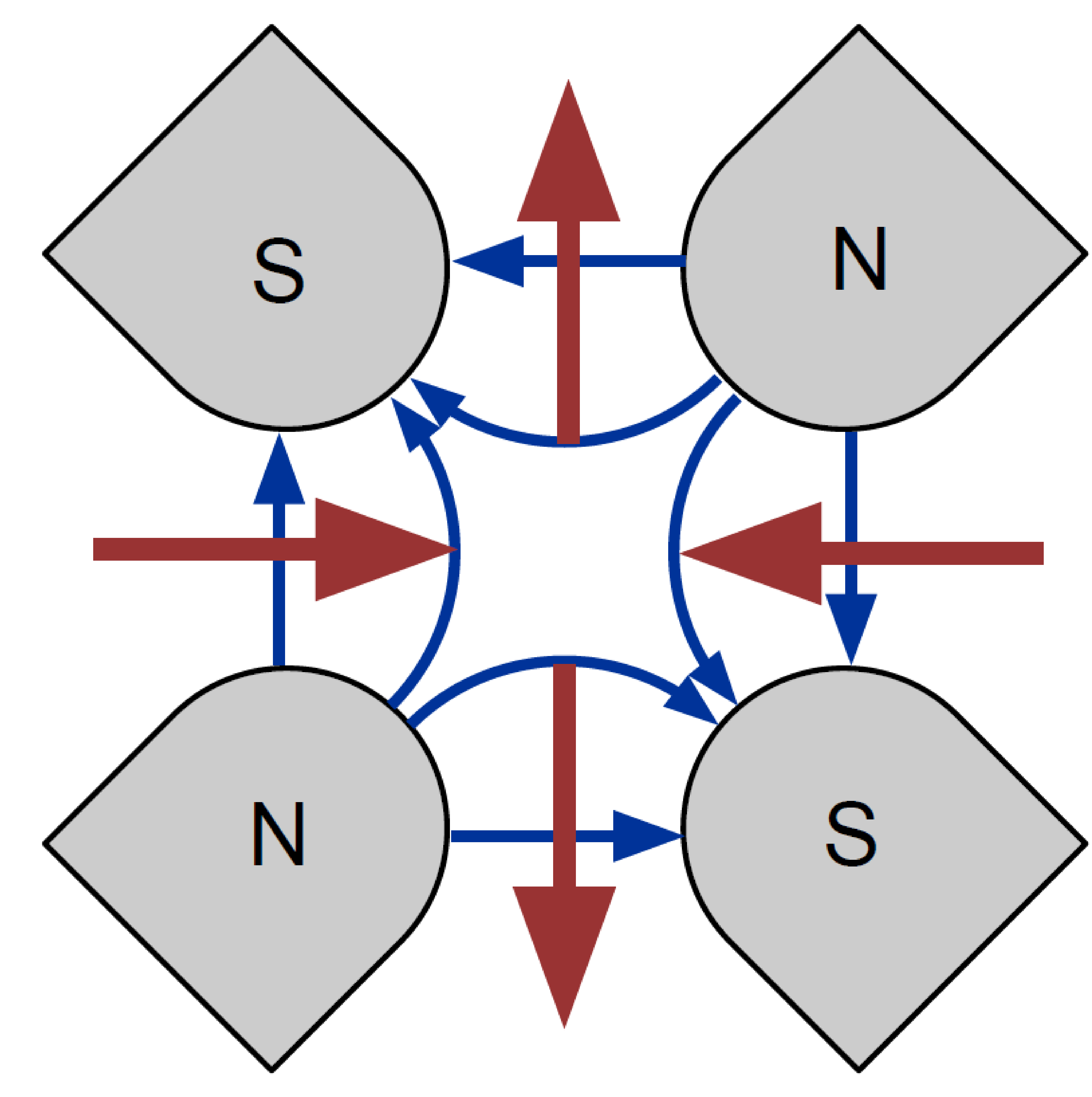

The blue lines show the direction of the magnetic field while the red show how the beam will be focused at the given polarity. This particular magnet would be classified as a focusing, or $F$ Quad, as it focuses in the horizontal plane and defocuses in the vertical [6].

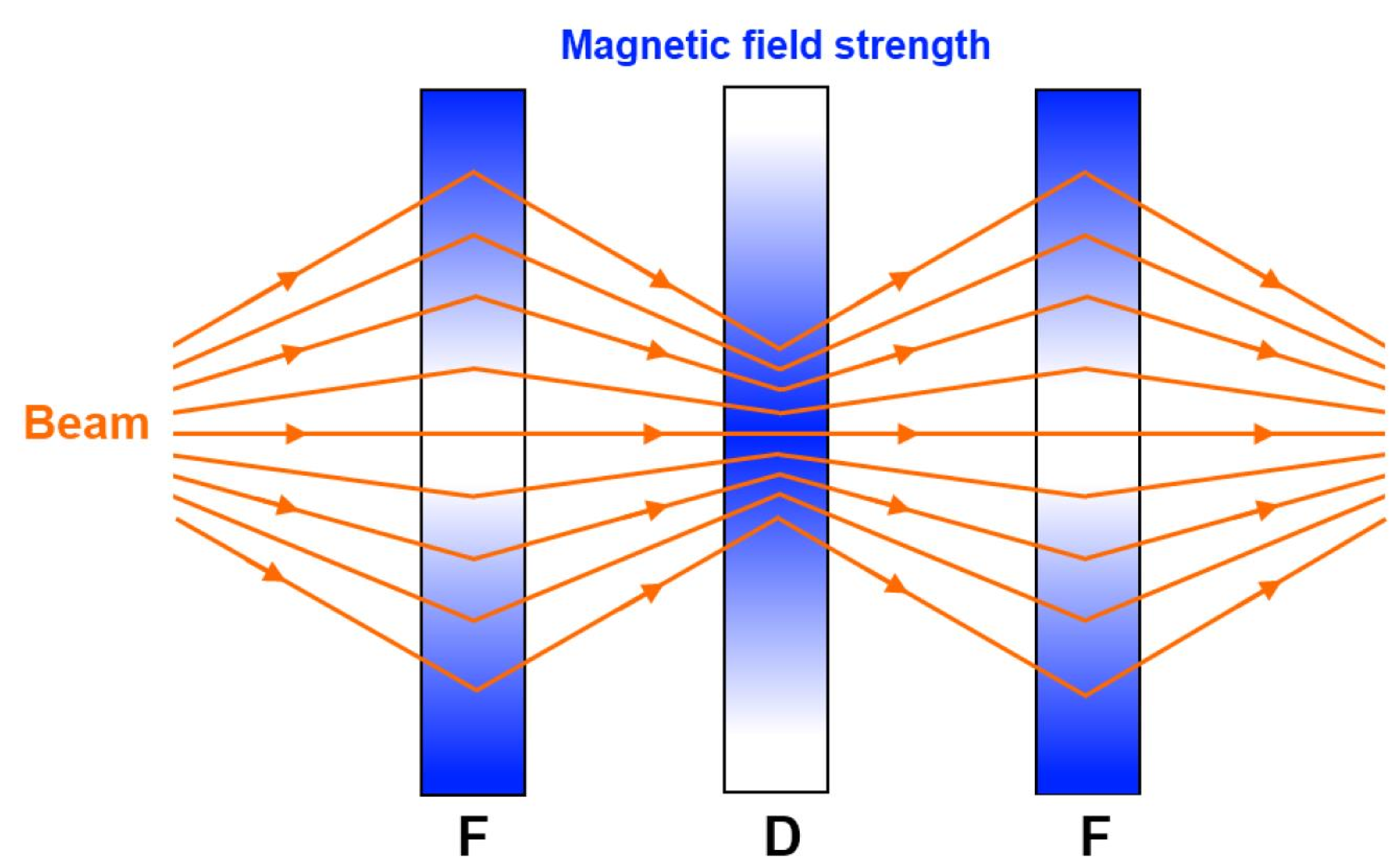

The blue and white color gradient is analogous to the magnetic field gradient. Defocusing quads have a negative gradient while focusing quads have a positive gradient. Alternating Gradient Focusing is displayed. A single unit for focusing is often referred to as a FODO cell. Multiple cells comprise a FODO lattice [6]. 


\section{Strong Focusing Basics - Part 3 : Focal Length}
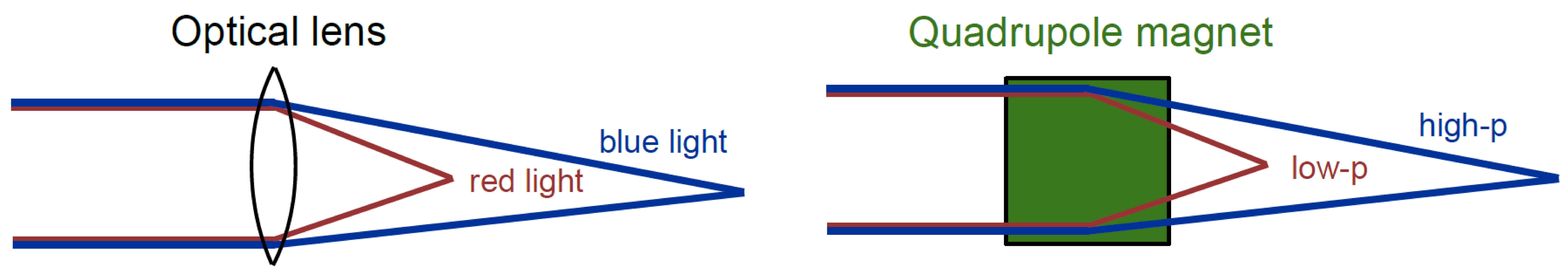

Similar to the longer focal lengths for higher frequency light, higher momentum particles focus further outward than low momentum particles [6]. 


\section{Momentum Acceptance Verification}

To confirm the minimum intensity of $5000 \mathrm{e}^{ \pm}$per spill at the experiment, optics for transport were designed.

- Though separation optics are not complete, study of bulk intensities delivered would better approximate what users could expect at different energies.

- A high loss estimate of 1 order for each intensity is assumed in calculations.

- Significant losses occur during beam separation.

- Magnetic transport channels must be tuned to specific momenta.

- $50 \mathrm{GeV} / \mathrm{c}$ momentum bite with a wide acceptance of about $\pm 20 \%$ was designed for FODO cell tuning.

- Placeholder optics were implemented to collimate the beam before injection into the lattice. 


\section{Target Production Site and Magnetic Transport Channel}

$2.186271 \mathrm{~m}$

2

1. Beryllium Target $30 \times 30 \times 453.5 \mathrm{~mm}^{3}$

2. Virtual Detector 1

Radius: $1 \mathrm{~m}$

Height: $50.8 \mathrm{~mm}$

3. Solenoid

Length: $0.4572 \mathrm{~m}$

Aperture Diameter: $76.2 \mathrm{~mm}$

4. Focusing Quad 1

Length: $0.2286 \mathrm{~m}$

Vertical Aperture Diameter: $76.2 \mathrm{~mm}$

Field Gradient: $95 \mathrm{~T} / \mathrm{m}$

5. 4Q120 Defocusing Quad

Length: $3.048 \mathrm{~m}$

Vertical Aperture Diameter: $101.6 \mathrm{~mm}$

Field Gradient: $-11.13051 \mathrm{~T} / \mathrm{m}$

6. 4Q120 Focusing Quad

Length: $3.048 \mathrm{~m}$

Vertical Aperture Diameter: $101.6 \mathrm{~mm}$

Field Gradient: $11.13051 \mathrm{~T} / \mathrm{m}$

7. Virtual Detector 2

Diameter: $101.6 \mathrm{~mm}$

5

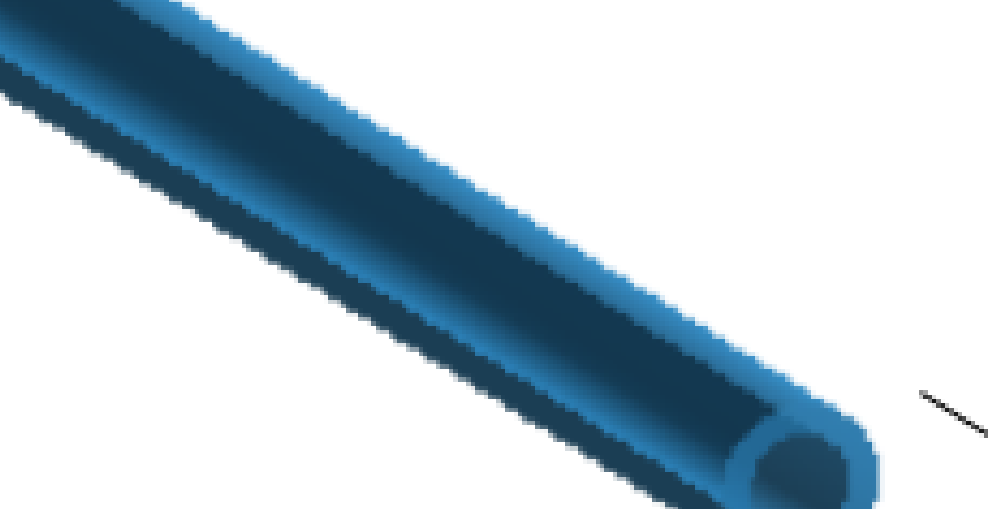

$5 m$

6

$2.5 \mathrm{~m}$ 
Intensity of $p$ Distribution with Magnetic Transport - $1^{\text {st }} 100$ meters


(Bin Width: $6 \mathrm{GeV} / \mathrm{c}$ ) 


\section{Intensity of $p$ Distribution with Magnetic Transport (continued)}

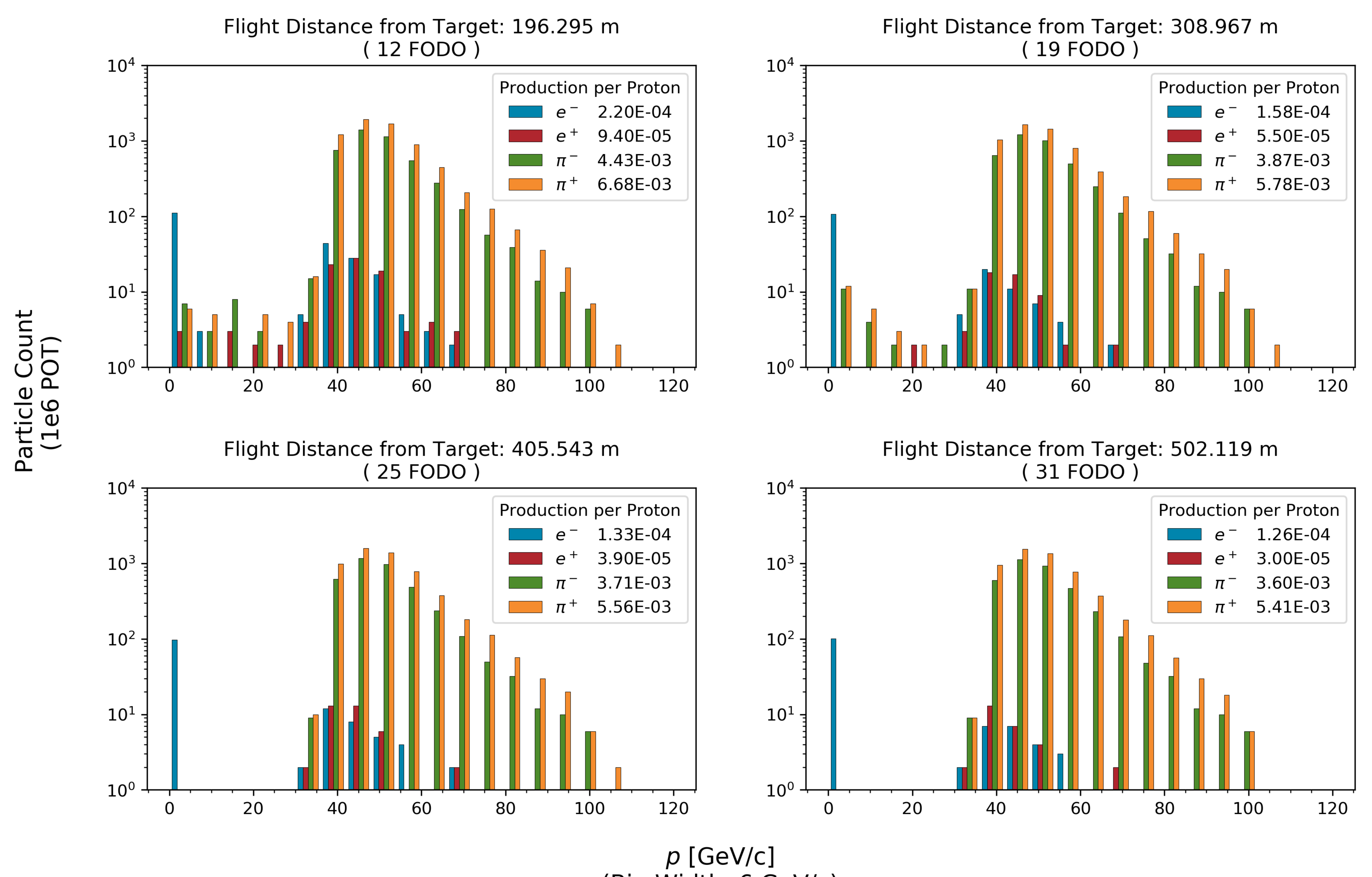

(Bin Width: $6 \mathrm{GeV} / \mathrm{c}$ )

$50 \mathrm{GeV} / \mathrm{c} p$ bite with $20 \%$ acceptance verified 


\section{Particle Beam Partial Composition Evolution}

Particle Beam Composition Evolution
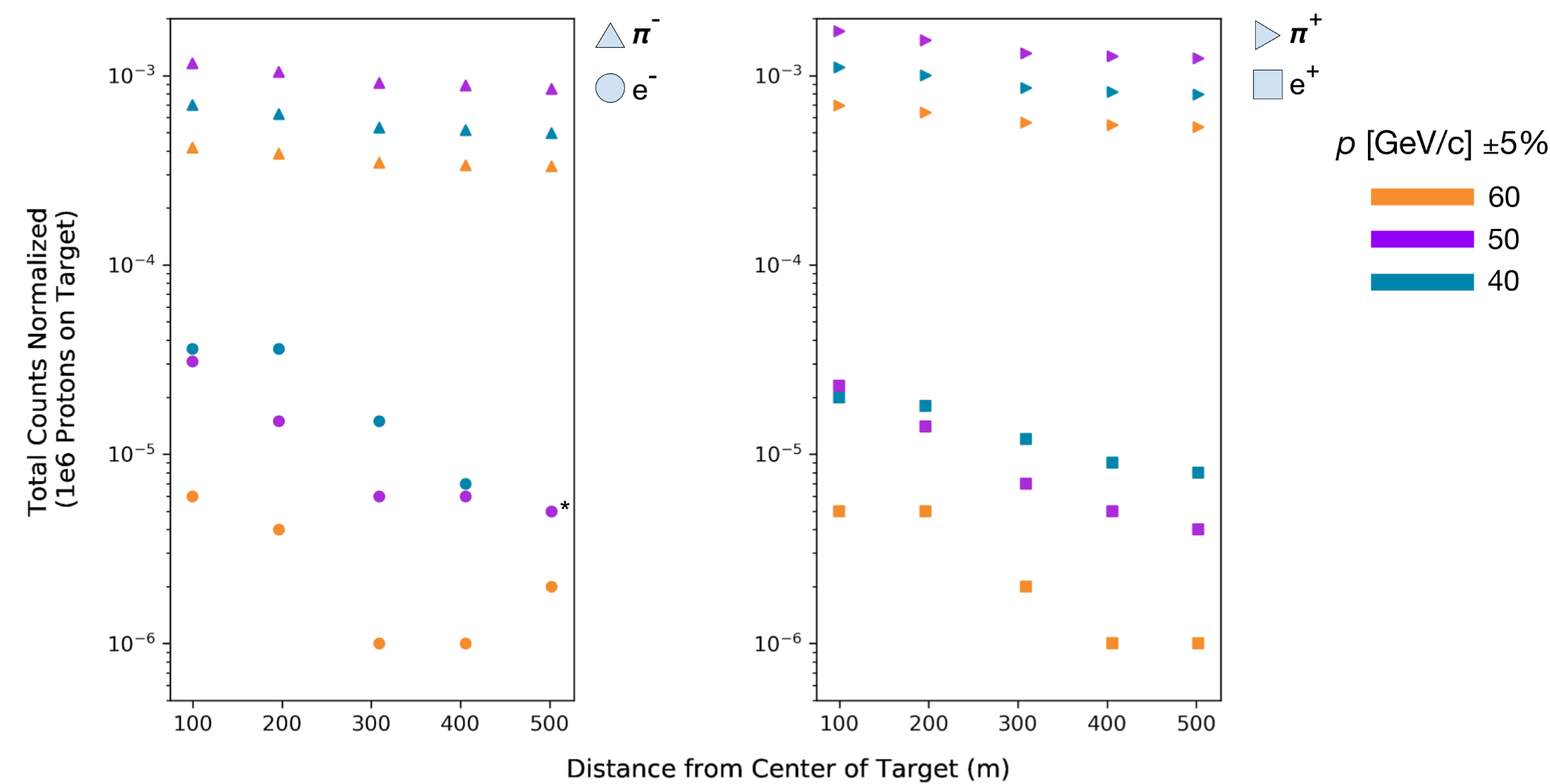

Normed Momentum Bite Counts at $500 \mathrm{~m}$

Strong focusing is tuned for $50 \mathrm{GeV} / \mathrm{c}$.

$10 \mathrm{ft}$ quad length allows for large acceptance of $\pm 20 \%$

: $5 e-6$ 6e-6

$50 \mathrm{GeV} / \mathrm{c}: 5 \mathrm{e}-6 \quad 4 \mathrm{e}-6$

$60 \mathrm{GeV} / \mathrm{c}: 2 \mathrm{e}-6$ 1e-6

${ }^{*}$ Marker for $40 \mathrm{GeV} / \mathrm{c} e^{-}$at $500 \mathrm{~m}$ is not visible as the $50 \mathrm{GeV} / \mathrm{c}$ $e^{-}$marker is on top. 


\section{Electron and Positron Intensity Delivered to Experiment}

\begin{tabular}{|c|c|c|c|c|}
\hline \multicolumn{4}{|c|}{ Expected Momentum Bite Intensity with 1 Order of Loss } \\
\hline \multirow{2}{*}{$p$ Bite $[\mathrm{GeV} / \mathrm{c}] \pm 5 \%$} & \multicolumn{2}{|c|}{ MT4 Proton Intensity: 2e11 } & \multicolumn{2}{c|}{ MT1 Proton Intensity: 1e13 } \\
\cline { 2 - 5 } & $\mathrm{e}^{-}$ & $\mathrm{e}^{+}$ & $\mathrm{e}^{-}$ & $\mathrm{e}^{+}$ \\
\hline 40 & $1 \mathrm{e} 5$ & $1.2 \mathrm{e} 5$ & $5 \mathrm{e} 6$ & $6 \mathrm{e} 6$ \\
\hline 50 & $1 \mathrm{e} 5$ & $8 \mathrm{e} 4$ & $5 \mathrm{e} 6$ & $4 \mathrm{e} 6$ \\
\hline 60 & $4 \mathrm{e} 4$ & $2 \mathrm{e} 4$ & $2 \mathrm{e} 6$ & $1 \mathrm{e} 6$ \\
\hline
\end{tabular}

${ }^{*}$ MT4 and MT1 reference enclosures of the Meson Beamline where target stations are located.

Minimum requested spill intensity for $\mathrm{e}^{-}$and $\mathrm{e}^{+}$is exceeded by 1 to 2 orders in MT4 and by 3 orders in MT1. Minimum requested energy is exceeded by $\sim 33 \%$ at $40 \mathrm{GeV} / \mathrm{c}$ bite to $\sim 100 \%$ at $60 \mathrm{GeV} / \mathrm{c}$ bite.

Further study is likely to yield significantly higher returns. 


\section{Next Phase}

- Identify the explicit production mechanisms of the chain reaction responsible for high-energy prompt $\mathrm{e}^{-}$and $\mathrm{e}^{+}$

- Confirm that the dominant contribution to $\mathrm{e}^{ \pm}$at the experiment are prompt in origin

- If species contribution from prompt production is significantly greater than that of charged pion decay, creating new material selection parameters and comparing the resulting material to Beryllium would be necessary.

- Design of species purification optics and verification in G4Beamline 


\section{References}

- [1] "H2 Beam Line." Cern.ch, CERN, 2017, http://sba.web.cern.ch/sba/BeamsAndAreas/resultbeam.asp?beamline=H2. Accessed 29 July 2018.

- [2] "Test Beams at DESY." Desy.de, Deutsches Elektronen-Synchrotron DESY, 2013, particle-physics.desy.de/e252106/. Accessed 29 July 2018.

- [3] "FACET-II Overview." Stanford.edu, Stanford University, 2016, https://facet.slac.stanford.edu/overview. Accessed 29 July 2018.

- [4] Pocanic, Dinko et al. "Experimental study of rare charged pion decays." Journal of Physics G: Nuclear and Particle Physics. Volume 41 Issue 11. 2014: 34 pg. iop.org. Web. http://iopscience.iop.org/article/10.1088/09543899/41/11/114002. Accessed 29 July 2018

- [5] Halkiadakis, Eva. "Lecture 3: Particle Interactions with Matter." Rutgers.edu, Rutgers University, 2009. www.physics.rutgers.edu/ evahal/talks/tasi09/TASI day3 school.pdf Accessed 29 July 2018. Accessed 30 July 2018.

- [6] Watts, Adam, et al. "Concepts Rookie Book." Fermilab Accelerator Division. PDF. December 3, 2013.

- [7] "G4beamline Release 3.04 Is Available (March 2017)." Muonsinternal.com, Muons Inc., www.muonsinternal.com/muons3/G4beamline\#Documentation. Accessed 30 July 2018.

- [8] "Geant4 Scope of Application." Cern.ch, GEANT4 Collaboration, http://geant4-userdoc.web.cern.ch/geant4userdoc/UsersGuides/IntroductionToGeant4/html/IntroductionToG4.html. Accessed 30 July 2018.

- [9] "Monte Carlo Method." Encyclopædia Britannica, Encyclopædia Britannica, Inc., 26 Sept. 2017, www.britannica.com/science/Monte-Carlo-method. Accessed 29 July 2018. Accessed 30 July 2018.

- [10] "Longer Term LHC Schedule." Cern.ch, CERN, https://lhc-commissioning.web.cern.ch/lhccommissioning/schedule/LHC-long-term.htm. Accessed 15 August 2018. 


\section{Acknowledgements}

Special thanks to

Carol Johnstone

Adam Watts

Jason St. John

Tom Roberts

John Johnstone

SIST Committee

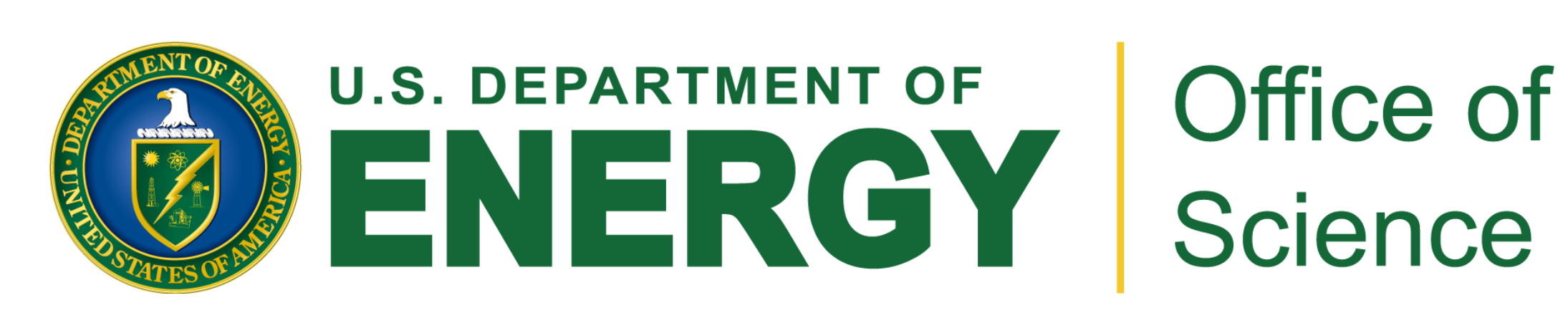

